\title{
Changes in the liquidity of closed-end country funds after the introduction of World Equity Benchmarks
}

\author{
Honghui Chen ${ }^{\mathrm{a}, 1}$, Joel N. Morse ${ }^{\mathrm{b}, *}$, Hoang Huy Nguyen ${ }^{\mathrm{b}, 2}$ \\ a College of Business Administration, University of Central Florida, Orlando, FL 32816-1400, United States \\ ${ }^{b}$ Merrick School of Business, University of Baltimore, Baltimore, MD 21201-5779, United States
}

\section{A R T I C L E I N F O}

\section{Article history:}

Received 21 March 2007

Received in revised form 30 January 2009

Accepted 26 February 2009

Available online 13 March 2009

\section{JEL classification:}

G12

\section{Keywords:}

Webs

ETF's

Market microstructure

Closed-end country funds

Complementary markets

\begin{abstract}
A B S T R A C T
In 1996, the first exchange-traded funds (ETFs) designed to track a subset of the Morgan Stanley Capital International country indices were approved under the name World Equity Benchmarks (acronym "WEBS"TM). We examine the impact of early WEBStrading on the liquidity of corresponding closed-end country funds (CECFs), previously one of the main avenues for retail investors to achieve country-specific equity exposure. We document a decline in both the trading volume and the trading frequency for CECFs, suggesting that some investors migrate to WEBS. At the same time, the market depth for CECFs increases and the bid-ask spread for CECFs decreases following the introduction of WEBS. Our results support the hypothesis that despite the decline in volume and trading frequency, the liquidity of CECFs is favorably affected by the advent of WEBS.
\end{abstract}

(C) 2009 The Board of Trustees of the University of Illinois. Published by Elsevier B.V. All rights reserved.

\section{Introduction}

The introduction of World Equity Benchmark Series (WEBS) on March 18, 1996 enhanced opportunities for international portfolio diversification. ${ }^{3}$ WEBS are country-specific equity portfolios that

\footnotetext{
* Corresponding author. Tel.: +1 4108374989.

E-mail addresses: honghui.chen@bus.ucf.edu (H. Chen), jmorse@ubalt.edu (J.N. Morse), hnguyen@ubalt.edu (H.H. Nguyen).

1 Tel.: +1 4078230895 .

2 Tel.: +1 4108375373 .

3 Although exchange-traded funds similar to WEBS are now known and traded as iShares (see, http://www.iShares.com, a trademark of Barclays Bank), and under other proprietary names, this paper will continue to employ the term WEBS because that term was commonly used during the study period.
} 
track the performance of country stock market indices. Prior to the introduction of WEBS, closed-end country funds (CECFs) trading on several U.S. exchanges were the major avenue for U.S. investors to gain international equity exposure with reasonable tracking error. WEBS have four main advantages over CECFs. First, they are passively managed to replicate the corresponding Morgan Stanley Capital International (MSCI) indices and hence offer a cheaper alternative to closed-end country funds (Chang \& Swales, 2003; Miffre, 2007). Second, WEBS can be sold short at any time during a trading day without the restriction of the uptick rule. Third, WEBS are superior to conventional closed-end funds in terms of tracking error. Because WEBS can be created and redeemed by large investors at net asset value (NAV), institutional investors can arbitrage away significant discounts or premia (Chang \& Swales, 2003). Finally, the creation-redemption mechanism helps keep unrealized capital gains for WEBS relatively low compared to CECFs and hence offers investors a tax-efficient advantage (Gastineau, 2002; Poterba \& Shoven, 2002).

Following the success of WEBS, similar financial innovations known as exchange-traded funds (ETFs) were introduced by financial intermediaries such as Barclays, Poweredge and Societe Generale. Currently, there are ETFs based on Morgan Stanley Capital International (MSCI) country indices, Goldman Sachs Commodity (GSCI) indices, traditional stock and bond market indices, sector indices and various other benchmarks. More than 200 ETFs are listed and traded on the NYSE Euronext Exchange, and options on over 75 ETFs are traded on the Chicago Board Options Exchange. The increasing popularity of WEBS and ETFs has motivated evaluation of changes in traditional markets and how WEBS have affected the liquidity of CECFs. Current empirical evidence over the latter question is limited. Khorana, Nelling, and Trester (1998) and O'Connor and Downe (2000) find that trading volume of CECFs is reduced, which suggests that the introduction of WEBS affects the size of the CECFs market. Other properties of liquidity, such as a market's 'tightness and depth' (Kyle, 1985) have not been sufficiently investigated. Therefore, the purpose of this study is to present a more comprehensive empirical analysis of how the advent of WEBS influenced the liquidity of CECFs market.

The literature on the interaction between financial instrument innovations and their corresponding or traditional markets suggests two possibilities. On one hand, the advent of a complementary market could negatively affect the quality of the original market. This occurs as uninformed traders are attracted by more favorable characteristics and migrate to the new market, leading to an increase in adverse selection cost and a decline in the original market's liquidity. Support for this hypothesis can be found in theoretical models of Subrahmanyam (1991) and Gorton and Pennacchi (1993) and in empirical findings by Jegadeesh and Subrahmanyam (1993) and Choi and Subrahmanyam (1994). On the other hand, Hegde and McDermott (2004) and Kumar, Sarin, and Shastri (1998) document a favorable impact on the underlying market liquidity as complementary instruments, namely stock options and index-tracking stocks, emerge. These authors suggest that because those newly introduced vehicles are superior for speculative purposes, informed traders will migrate to the new market, hence reducing the information asymmetry and improving the market liquidity of the traditional instruments. In the context of the interaction between WEBS and CECFs, because WEBS have a low tracking error and are not subject to the uptick rule for short sales, they could attract informed traders. In the sense of the mechanisms suggested by Hegde and McDermott (2004) and Kumar et al. (1998), WEBS could positively affect the market liquidity for CECFs.

Examining the 1996-2000 period, we find that the liquidity of CECFs improves as the bid-ask spread drops more than $2 \%$ and the quote depth increases by more than $40 \%$ following the introduction of WEBS. Also, we find that the reduction in trading volume documented so far in the literature is a result of a decline in the number of daily trades rather than a decline in the average trade size. Finally, in terms of the relative liquidity between WEBS and CECFs, we find that the new WEBS are more liquid than the predecessor CECFs. In general, our study supports the hypothesis that complementary markets can improve the liquidity of the original market.

The remainder of this paper is organized in four sections. A literature review and alternative hypotheses concerning the impact of WEBS on the liquidity of CECFs are presented in Section 2 . The data and methodology are presented in Section 3. Section 4 reports the empirical analysis of the impact of WEBS on the market liquidity of CECFs. We conclude our paper in Section 5. 


\section{Literature review and hypotheses}

While theory does not directly generate any predictions about the impact of the introduction of WEBS on CECFs liquidity, existing studies on financial innovation imply two possibilities. The first hypothesis holds that new derivative or complementary market could adversely affect the liquidity of the original market as uninformed traders migrate to the new one. Subrahmanyam (1991) argues that components of adverse selection costs that specifically pertain to individual securities will be diversified away in the market for composite investment vehicles, thereby lowering transaction costs. As a result, liquidity-motivated traders will choose to execute their trades in the "composite" market. Similarly, Gorton and Pennacchi (1993) show that composite securities provide an alternative with lower transaction costs and hence attract liquidity traders from the underlying market. According to Gorton and Pennacchi (1993) and Subrahmanyam (1991) models, as uninformed traders migrate to the composite market, the underlying security will experience more severe information asymmetry, leading to declines in liquidity, which in turn is reflected in increased bid-ask spreads and reduced quote depth. In support of these two models, Jegadeesh and Subrahmanyam (1993) find that the bidask spread for the underlying component securities increases by about 3.7\% upon the introduction of the Standard and Poor's (S\&P) 500 index futures contract. Similarly, Choi and Subrahmanyam (1994), examining the impact of the introduction of the Major Market Index (MMI) futures contract on the liquidity and volatility of that index's component securities, find that following the advent of the MMI futures instrument, the average intraday bid-ask spread for the underlying equities increases and note no significant change in intraday volatility. These findings support the hypothesis that the liquidity of the cash market is negatively affected by the existence of composite instruments either because uninformed traders migrate to the new markets or because the introduction of a new vehicle stimulates additional informed speculation on market-wide factors.

In the context of global diversification, there are reasons to believe that upon the introduction of WEBS, liquidity traders might leave the traditional CECFs market. First, for the purpose of global diversification, WEBS can serve as an ideal complement to existing vehicles and strategies. For example, Pennathur, Delcuore, and Anderson (2002) show that the price of CECFs is influenced more by the U.S market than WEBS. Because shares, or units of WEBS can be created and redeemed at the fund's net asset value on a daily basis, institutions with large long or short positions in WEBS or in individual foreign equities can arbitrage any significant discrepancy between NAV and the WEBS price, thereby enhancing close tracking with regards to a fund's stock constituents. Khorana et al. (1998) document that WEBS closely track their appropriate MSCI country indices and that they exhibit low correlation with the S\&P 500 index, thus suggesting that the diversification benefit of foreign equity indices is also present in the corresponding WEBS. Similarly, Harper, Madura, and Schnusenberg (2006) show that the returns of WEBS are not significantly different from those of the MSCI indices. They also find that WEBS offer higher Sharpe ratios than competing CECFs. Moreover, Miffre (2007) shows that WEBS can provide a global diversification advantages that cannot be obtained using CECFs. Phengpis and Swanson (2004), using data from 2000 to 2003, find that since investors cannot invest directly in country-specific indices, studies of international diversification based on indices overstate the gains. The authors test diversification both with individual equities and with ETFs (iShares, in particular) and conclude that there are diversification gains from efficient portfolios of ETFs.

Second, due to the above-described mechanism of unit creation and redemption, WEBS arbitrageurs can minimize significant discounts or premia with respect to NAV. Hence, liquidity traders are spared price uncertainty due to non-fundamental sources, a problem encountered in the pricing of CECFs. For example, Patro (2005) documents that the listing of new CECFs results in a short-term drop in the premia on other funds for the same country. Lee and Hong (2002) suggest that the sentiment of U.S. investors can significantly influence performance of CECFs.

Third, WEBS, due to their passive index-mimicking approach to choosing the underlying securities, are superior to more actively managed CECFs in terms of the annual fees charged. Chang and Swales (2003) document that the average expense ratio of WEBS is $0.87 \%$, which is about half the prevailing fee for CECFs. Finally, compared to actively managed CECFs, WEBS offer investors a capital gains tax advantage due to low trading turnover and thus lowers future capital gains (Gastineau, 2001). The 
diversification and cost advantages of WEBS potentially attract liquidity traders from the CECFs market and therefore could adversely affect the liquidity of CECFs.

The second hypothesis holds that the liquidity of the predecessor market will improve as informed traders migrate to the new market. Kumar et al. (1998) examine the impact of option trading on the underlying security and argue that as the derivative better facilitates speculative purposes, traders with private information will move to the new market. Also, they suggest that the introduction of complementary markets will increase the market-wide level of public information. These trends help to lower information asymmetry and make the original market more efficient, characterized by lower spreads and increased quote depth. Empirical results are consistent their predictions. Hegde and McDermott (2004) offer further elucidation of increased liquidity for a predecessor instrument after a similar or complimentary trading vehicle emerges. Specifically, the introduction of DIAMONDS and Q's, respectively index-tracking stocks for the Dow Jones Industrial Average and the NASDAQ 100 index, led to increased liquidity in the underlying individual component stocks. The decreased spreads and higher volumes arise, according to the authors, from the improved arbitrage opportunities offered to informed traders by the new vehicles. While the portfolio vehicle (DIAMONDS and Q's) enjoys greater liquidity than the underlying securities, both markets are characterized by improved operational efficiency. In terms of the interaction between WEBS and CECF, WEBS can be an attractive vehicle to informed traders who are presumably knowledgeable about the value of the index portfolio. The reason is that WEBS are not subject to the uptick rule and therefore informed traders can sell short at any time during the trading day. Also, the fact that WEBS are better able to track an index helps informed traders invest and hedge based on foreign market conditions with less risk associated with non-fundamental factors. In the spirit of Kumar et al. (1998) and Hegde and McDermott (2004) those features could attract informed traders away from the underlying market. As a result, it is possible that the introduction of WEBS will improve the liquidity of CECFs.

\section{Data and methodology}

We obtain background information for WEBS and CECFs from the American Stock Exchange (AMEX) website and from the Center for Research in Security Prices (CRSP). We use the New York Stock Exchange's (NYSE) Trades and Quotes (TAQ) database to get detailed information on all trades and quotes for stocks listed on the NYSE, the AMEX, and NASDAQ. Our analysis is centered on those CECFs that have corresponding WEBS. Table 1 shows 29 CECFs that correspond to 17 WEBS. Ticker symbols for all securities are provided. The majority of the WEBS were introduced in 1996, although the WEBS for South Korea, Taiwan and Brazil were introduced in 2000.

We focus on three liquidity measures. First, we examine order flows, proxied by daily volume and its two components, the average trade size and the number of trades per day. Our examination enables us to pinpoint the cause of the changes in daily volume. Second, we analyze the pattern of the quote depth, which is the number of shares available on the bid and the ask sides of a given quote. We also examine the dollar depth, which is the average value of shares available at the bid and ask. Finally, we calculate the dollar bid-ask spread, the absolute difference between the ask price and the bid price, and the percentage spread, which is the ratio between the dollar spread and the average of the ask price and the bid price. Since intraday quoted spreads have a U-shaped pattern, we follow the method in Kumar et al. (1998) to come up with a weighted average of spread and depth for each day, where the weight is the fraction of the day that the quote is valid (i.e., displayed for traders).

For each eligible CECF, we calculate the median daily value of each liquidity measure for 3 months before (pre-WEBS) and 3 months after (post-WEBS) the introduction of WEBS. We then analyze the pre-WEBS to post-WEBS ratio to quantify inferences about the impact of the WEBS introductions on the CECFs market. To control for possible structural changes among CECFs around the event dates, we adjust the liquidity measures for each of the 29 target CECFs with the average level of a control sample of other closed-end funds (including other CECFs). Specifically, on each event date, we rank the universe of closed-end funds (those that have a share code of either 14 or 15 in the CRSP file) into 
Table 1

WEBS and their corresponding closed-end country funds.

\begin{tabular}{|c|c|c|c|c|c|}
\hline \multicolumn{3}{|l|}{ WEBS } & \multicolumn{3}{|l|}{ Closed-end country fund } \\
\hline Name & Ticker & Introduction date & Name & Ticker & Introduction date \\
\hline MSCI-Australia & EWA & 03/18/1996 & Aberdeen Australia Equity Fd Inc. & IAF & $12 / 16 / 1985$ \\
\hline MSCI-Austria & EWO & 03/18/1996 & Austria Fund Inc. & OST & 09/22/1989 \\
\hline MSCI-Canada & EWC & 03/18/1996 & Central Fund Canada Ltd. & CEF & 04/03/1986 \\
\hline MSCI-France & EWQ & 03/18/1996 & France Growth Fund Inc. & FRF & 05/11/1990 \\
\hline MSCI-Germany & EWG & 03/18/1996 & $\begin{array}{l}\text { Germany Fund Inc. } \\
\text { New Germany Fund Inc. } \\
\text { Emerging Germany Fund Inc. }\end{array}$ & $\begin{array}{l}\text { GER } \\
\text { GF } \\
\text { FRG }\end{array}$ & $\begin{array}{l}07 / 18 / 1986 \\
01 / 25 / 1990 \\
03 / 29 / 1990\end{array}$ \\
\hline MSCI-Hong Kong & EWH & 03/18/1996 & $\begin{array}{l}\text { China Fund Inc. } \\
\text { Greater China Fund Inc. } \\
\text { Jardine Fleming China Region Fd } \\
\text { Templeton China World Fund Inc. }\end{array}$ & $\begin{array}{l}\text { CHN } \\
\text { GCH } \\
\text { JFC } \\
\text { TCH }\end{array}$ & $\begin{array}{l}07 / 10 / 1992 \\
07 / 15 / 1992 \\
07 / 16 / 1992 \\
09 / 09 / 1993\end{array}$ \\
\hline MSCI-U.K. & EWU & 03/18/1996 & United Kingdom Fund Inc. & UKM & 08/07/1987 \\
\hline MSCI-Italy & EWI & 03/18/1996 & Italy Fund Inc. & ITA & $02 / 26 / 1986$ \\
\hline MSCI-Switzerland & EWL & 03/18/1996 & Swiss Helvetia Fund Inc. & SWZ & 08/19/1987 \\
\hline MSCI-Spain & EWP & 03/18/1996 & $\begin{array}{l}\text { Spain Fund Inc. } \\
\text { Growth Fund Of Spain Inc. }\end{array}$ & $\begin{array}{l}\text { SNF } \\
\text { GSP }\end{array}$ & $\begin{array}{l}06 / 21 / 1988 \\
02 / 12 / 1990\end{array}$ \\
\hline MSCI-Singapore & EWS & 03/18/1996 & Singapore Fund Inc. & SGF & $07 / 25 / 1990$ \\
\hline MSCI-Mexico & EWW & 03/18/1996 & $\begin{array}{l}\text { Mexico Fund Inc. } \\
\text { Mexico Equity \& Income Fund } \\
\text { Emerging Mexico Fund Inc. }\end{array}$ & $\begin{array}{l}\text { MXF } \\
\text { MXE } \\
\text { MEF }\end{array}$ & $\begin{array}{l}06 / 08 / 1981 \\
08 / 15 / 1990 \\
10 / 02 / 1990\end{array}$ \\
\hline MSCI-Malaysia & EWM & 03/18/1996 & Malaysia Fund Inc. & MF & 05/08/1987 \\
\hline MSCI-Japan & EWJ & 03/18/1996 & $\begin{array}{l}\text { Japan Smaller Cap Fund Inc. } \\
\text { Japan Equity Fund Inc. }\end{array}$ & $\begin{array}{l}\text { JOF } \\
\text { JEQ }\end{array}$ & $\begin{array}{l}03 / 14 / 1990 \\
08 / 14 / 1992\end{array}$ \\
\hline MSCI-South Korea & EWY & $05 / 12 / 2000$ & $\begin{array}{l}\text { Korea Fund Inc. } \\
\text { Korean Investment Fund Inc. } \\
\text { Korea Equity Fund Inc. }\end{array}$ & $\begin{array}{l}\mathrm{KF} \\
\mathrm{KIF} \\
\mathrm{KEF}\end{array}$ & $\begin{array}{l}08 / 22 / 1984 \\
02 / 14 / 1992 \\
11 / 24 / 1993\end{array}$ \\
\hline MSCI-Taiwan & EWT & $06 / 23 / 2000$ & Taiwan Fund Inc. & TWN & $12 / 16 / 1986$ \\
\hline MSCI-Brazil & EWZ & $07 / 14 / 2000$ & $\begin{array}{l}\text { Brazil Fund Inc. } \\
\text { Brazilian Equity Fund Inc. }\end{array}$ & $\begin{array}{l}\text { BZF } \\
\text { BZL }\end{array}$ & $\begin{array}{l}03 / 31 / 1988 \\
04 / 03 / 1992\end{array}$ \\
\hline
\end{tabular}

This table lists the WEBS and their corresponding closed-end country funds. Information for WEBS is obtained from AMEX website, and information for corresponding closed-end country funds is obtained from the Center for Research in Security Prices (CRSP).

quintiles based on the average of daily trading volume during the previous 3 months. ${ }^{4}$ Those closedend funds that are not associated with any WEBS introduction but are in the same volume quintile as the target CECFs will serve as the control sample for that target CECFs. Following Chen, Noronha, and Singal (2004), we form the abnormal ratio by dividing the post/pre ratio of target CECFs by the average ratio of the control sample.

\section{Results}

Our first analysis concerns the order flow for CECFs around the introduction of WEBS. Specifically, for each CECF that has a correspondent WEBS, we analyze the trading activities for 3 months before and after the introduction of WEBS, referred to as pre and post periods, respectively. ${ }^{5}$ For each CECF,

\footnotetext{
${ }^{4}$ A similar analysis that controls for market capitalization yields results comparable to those reported here.

${ }^{5}$ We use the 3-month window in order to balance between a desire to avoid any structural changes over a long period of time and a need for the necessary statistical power associated with a sufficient time period. In a robustness check not reported
} 
we report the median daily values of trading volume, trade size and number of trade for each period. We then calculate the post/pre ratio for each measure of liquidity. The results are reported in Table 2 . In Panel A, we see a large decline in daily trading volume for CECFs after the emergence of WEBS. Across the set of 29 CECFs, the average (median) of the post-WEBS daily volume is $40,390(27,800)$ shares, compared with 55,500 (37,550) shares for the pre-WEBS period, resulting in a decline of about $27 \%$. As expected, both mean and median of the post/pre ratio are less than 1 and statistically different from 1 at $1 \%$ level. In the last column, we report abnormal post/pre ratio. The median abnormal ratio of 0.965 suggests that compare to its peer, target CECFs experience a 3.5\% reduction in trading volume. The result is significant only for the median value.

The panel's finding is consistent with Khorana et al. (1998) who also document a significant reduction of trading activities for CECFs around the introduction dates of WEBS. Our finding also supports O'Connor and Downe's (2000) rational economic hypothesis that average investors migrate to lower management fee WEBS, and thus CECFs trading volume declines. However, our results appear to be at odds with Kumar et al. (1998) and Hegde and McDermott (2004) who, respectively, find a significant and an insignificant increase in trading volume for the underlying market around the introduction of options and the introduction of composite instruments.

In the next two panels, we investigate the reason behind the observed reduction in volume. Panel $B$ shows that changes in trade size for CECFs around the introduction of WEBS are small in magnitude and statistically insignificant, especially for the abnormal numbers. Panel $\mathrm{C}$ reports that the number of trades per day significantly decreases after the introduction of WEBS. The mean and median declines are both about $25 \%$. The abnormal reduction is about $6 \%$, statistically significant. The magnitude of the decline in the number of trades per day is similar to the size of change in daily trading volume.

The three panels show that the decline in trading volume results from the decrease in the number of trades per day, rather than from the change in the average trade size. On one hand, this suggests that WEBS reduce the liquidity of CECFs by luring investors away. On the other hand, as there is no significant reduction in the average trade size, we expect that certain liquidity aspects of CECFs are not significantly affected by WEBS. To further investigate the liquidity issue, we examine the how quoted depth and spread for CECFs vary as WEBS trading begins.

Table 3 shows results for the quote depth and the bid-ask spread. Similar to Table 2, we report the median daily values of those two liquidity measures for pre and post periods together with the post/pre ratios. Panel A investigates the dollar depth which is the average value of the number of shares available at the bid and ask prices that comprise each quote. Following the introduction of WEBS, the average (median) increase in market depth for CECFs is about $45 \%$ (24\%), statistically significant at $1 \%$ level. Some funds such as BZL, FRF, or MXE experience a huge quote depth increase of more than $100 \%$. Compared to the control sample, those CECFs with WEBS also show a significant increase in depth of $27 \%(8 \%)$ in mean (median).

Panel B corroborates the finding of Panel A with depth calibrated in number of shares. After WEBS trading commences, the mean (median) market depth for CECFs increases by statistically significant $47 \%$ (27\%). The abnormal increase is about $27 \%$ for the mean and $8 \%$ for the median value. The changes in depth are economically large, which suggests that the introduction of WEBS favorably influences the liquidity conditions of CECFs. It should be noted that that in a comparable setting, Hegde and McDermott (2004) find a meaningful but smaller change of depth in the 30 Dow Jones Industrial securities following the advent of DIAMONDS. Such a difference in changes in depth between our study and Hegde and McDermott (2004) is reasonable because the 30 Dow stocks are very large, seasoned and heavily traded stocks which do not suffer severely from information asymmetry. Therefore, the arrival of a complementary investment vehicle is not likely to substantially improve market liquidity. However, since CECFs are comprised of smaller and more thinly traded companies with less available information, the introduction of complementary vehicles should have a stronger impact on alleviating the information asymmetry. 
Table 2

Closed-end country fund order flow after the introduction of WEBS.

\begin{tabular}{|c|c|c|c|c|}
\hline Ticker symbol & Pre-level & Post-level & Post/pre & Target ratio/control ratio \\
\hline \multicolumn{5}{|c|}{ Panel A. Change in daily trade volume (hundred of shares) } \\
\hline BZF & 314.5 & 280.0 & 0.890 & 0.996 \\
\hline BZL & 140.0 & 160.0 & 1.143 & 1.236 \\
\hline CEF & 379.5 & 275.0 & 0.725 & 1.003 \\
\hline $\mathrm{CHN}$ & 484.5 & 252.5 & 0.521 & 0.721 \\
\hline FRF & 443.5 & 328.0 & 0.740 & 1.023 \\
\hline FRG & 348.5 & 296.0 & 0.849 & 1.175 \\
\hline $\mathrm{GCH}$ & 374.0 & 524.0 & 1.401 & 1.939 \\
\hline GER & 395.0 & 275.5 & 0.697 & 0.965 \\
\hline GF & 822.5 & 684.0 & 0.832 & 1.078 \\
\hline GSP & 494.0 & 278.0 & 0.563 & 0.779 \\
\hline IAF & 511.5 & 285.0 & 0.557 & 0.722 \\
\hline ITA & 176.5 & 149.5 & 0.847 & 1.135 \\
\hline JEQ & 530.5 & 264.0 & 0.498 & 0.645 \\
\hline JFC & 344.5 & 287.5 & 0.835 & 1.155 \\
\hline JOF & 375.5 & 323.0 & 0.860 & 1.190 \\
\hline KEF & 268.0 & 157.5 & 0.588 & 0.734 \\
\hline $\mathrm{KF}$ & 2311.0 & 1845.5 & 0.799 & 0.955 \\
\hline KIF & 237.5 & 144.5 & 0.608 & 0.760 \\
\hline MEF & 487.0 & 350.5 & 0.720 & 0.996 \\
\hline $\mathrm{MF}$ & 360.5 & 221.0 & 0.613 & 0.848 \\
\hline MXE & 518.0 & 420.5 & 0.812 & 1.052 \\
\hline MXF & 3091.5 & 2337.5 & 0.756 & 0.980 \\
\hline OST & 264.5 & 162.0 & 0.612 & 0.821 \\
\hline SGF & 289.0 & 158.0 & 0.547 & 0.756 \\
\hline SNF & 258.0 & 159.0 & 0.616 & 0.826 \\
\hline SWZ & 312.0 & 245.5 & 0.787 & 1.089 \\
\hline $\mathrm{TCH}$ & 906.5 & 454.0 & 0.501 & 0.649 \\
\hline TWN & 590.0 & 355.5 & 0.603 & 0.718 \\
\hline UKM & 68.0 & 40.0 & 0.588 & 0.745 \\
\hline Mean & 555.0 & 403.9 & $0.728^{* * *}$ & 0.955 \\
\hline Median & 375.5 & 278.0 & $0.720^{* * *}$ & $0.965^{*}$ \\
\hline \multicolumn{5}{|c|}{ Panel B. Average trade size (hundred of shares) } \\
\hline BZF & 11.2 & 10.3 & 0.915 & 0.931 \\
\hline BZL & 13.7 & 15.6 & 1.144 & 1.139 \\
\hline CEF & 18.5 & 19.0 & 1.028 & 1.107 \\
\hline $\mathrm{CHN}$ & 11.2 & 9.6 & 0.862 & 0.929 \\
\hline FRF & 15.4 & 16.5 & 1.072 & 1.155 \\
\hline FRG & 13.8 & 14.4 & 1.043 & 1.123 \\
\hline $\mathrm{GCH}$ & 8.1 & 11.4 & 1.408 & 1.517 \\
\hline GER & 10.8 & 8.6 & 0.793 & 0.854 \\
\hline GF & 11.9 & 12.3 & 1.041 & 1.117 \\
\hline GSP & 15.4 & 11.7 & 0.760 & 0.819 \\
\hline IAF & 12.6 & 10.6 & 0.846 & 0.907 \\
\hline ITA & 14.6 & 13.7 & 0.936 & 1.011 \\
\hline JEQ & 11.8 & 9.8 & 0.833 & 0.894 \\
\hline JFC & 11.9 & 11.1 & 0.934 & 1.006 \\
\hline JOF & 11.6 & 12.1 & 1.049 & 1.130 \\
\hline KEF & 20.3 & 15.8 & 0.781 & 0.792 \\
\hline $\mathrm{KF}$ & 26.5 & 27.0 & 1.020 & 1.012 \\
\hline KIF & 14.5 & 12.5 & 0.865 & 0.877 \\
\hline MEF & 12.2 & 13.1 & 1.081 & 1.164 \\
\hline $\mathrm{MF}$ & 9.1 & 8.6 & 0.942 & 1.014 \\
\hline MXE & 10.0 & 12.5 & 1.250 & 1.341 \\
\hline MXF & 16.2 & 18.4 & 1.137 & 1.219 \\
\hline OST & 16.7 & 10.9 & 0.648 & 0.701 \\
\hline SGF & 9.0 & 8.2 & 0.904 & 0.974 \\
\hline SNF & 9.7 & 8.4 & 0.873 & 0.943 \\
\hline SWZ & 8.3 & 6.8 & 0.825 & 0.889 \\
\hline $\mathrm{TCH}$ & 10.5 & 10.3 & 0.978 & 1.049 \\
\hline
\end{tabular}


Table 2 (Continued)

\begin{tabular}{|c|c|c|c|c|}
\hline Ticker symbol & Pre-level & Post-level & Post/pre & Target ratio/control ratio \\
\hline TWN & 22.0 & 15.4 & 0.701 & 0.720 \\
\hline UKM & 7.9 & 7.1 & 0.900 & 0.959 \\
\hline Mean & 13.3 & 12.5 & 0.951 & 1.010 \\
\hline Median & 11.9 & 11.7 & $0.934^{*}$ & 1.006 \\
\hline \multicolumn{5}{|c|}{ Panel C. Number of trades per day (hundred trade) } \\
\hline BZF & 26.5 & 27.0 & 1.019 & 1.089 \\
\hline BZL & 10.5 & 10.0 & 0.952 & 1.019 \\
\hline CEF & 23.5 & 15.5 & 0.660 & 0.848 \\
\hline $\mathrm{CHN}$ & 45.5 & 26.5 & 0.582 & 0.749 \\
\hline FRF & 29.0 & 17.5 & 0.603 & 0.776 \\
\hline FRG & 28.0 & 18.5 & 0.661 & 0.849 \\
\hline $\mathrm{GCH}$ & 44.0 & 49.5 & 1.125 & 1.446 \\
\hline GER & 35.5 & 28.5 & 0.803 & 1.032 \\
\hline GF & 67.5 & 53.0 & 0.785 & 0.964 \\
\hline GSP & 30.0 & 24.0 & 0.800 & 1.028 \\
\hline IAF & 41.0 & 28.5 & 0.695 & 0.853 \\
\hline ITA & 12.0 & 9.5 & 0.792 & 1.013 \\
\hline JEQ & 45.0 & 29.0 & 0.644 & 0.791 \\
\hline JFC & 29.0 & 26.0 & 0.897 & 1.152 \\
\hline JOF & 33.0 & 25.0 & 0.758 & 0.974 \\
\hline KEF & 12.0 & 9.0 & 0.750 & 0.942 \\
\hline $\mathrm{KF}$ & 78.5 & 63.5 & 0.809 & 0.999 \\
\hline KIF & 17.0 & 11.0 & 0.647 & 0.812 \\
\hline MEF & 40.5 & 29.5 & 0.728 & 0.936 \\
\hline MF & 35.0 & 24.5 & 0.700 & 0.900 \\
\hline MXE & 44.0 & 32.5 & 0.739 & 0.906 \\
\hline MXF & 194.5 & 134.0 & 0.689 & 0.845 \\
\hline OST & 16.0 & 12.0 & 0.750 & 0.960 \\
\hline SGF & 29.0 & 19.0 & 0.655 & 0.842 \\
\hline SNF & 29.0 & 18.0 & 0.621 & 0.795 \\
\hline SWZ & 37.5 & 32.0 & 0.853 & 1.097 \\
\hline $\mathrm{TCH}$ & 72.0 & 47.0 & 0.653 & 0.801 \\
\hline TWN & 26.5 & 22.5 & 0.849 & 0.987 \\
\hline UKM & 8.0 & 6.0 & 0.750 & 0.910 \\
\hline Mean & 39.3 & 29.3 & $0.758^{* * *}$ & $0.942^{* *}$ \\
\hline Median & 30.0 & 25.0 & $0.750^{* * *}$ & $0.936^{* * *}$ \\
\hline
\end{tabular}

For each closed-end fund, we obtain the median daily volume, median trade size, and median number of trades per day for 3 months before and the 3 months after the introduction of the corresponding WEBS. We calculate the ratio of the postintroduction level to the pre-introduction level. In the last column, we report the ratio of the post/pre ratio of target CECFs to the average ratio of control sample. Each event date, we rank the universe of closed-end funds into quintiles based on the average of daily trading volume during the previous 3 months. Those that are in the same volume quintile as the target CECFs and that are not associated with any WEBS introduction will serve as the control sample for that target CECFs.

The significant levels for mean and median of the ratio are determined by standard $t$-test and Wilcoxon signed-rank test, respectively. ${ }^{* * *},{ }^{* *}$, and ${ }^{*}$ denote significant at $0.01,0.05$, and 0.1 , respectively.

The signed-rank test statistic $S$ is computed as $S=\sum_{i ; x_{i}>0} r_{i}^{+}-\left(n_{t}\left(n_{t}+1\right) / 4\right)$, where (i) $r_{i}^{+}$is the rank of the absolute difference between the individual ratio and 1 , which underlies the hypothesis that there is no significant changes in trading activities for CECFs around the introduction of WEBS and (ii) $n_{t}$ is the number of observations not equal to 1 . For details for the test procedure, refer to Lehmann (1998).

In Panels $C$ and $D$, we examine changes in dollar and percentage spread. In Panel C, the dollar spread for CECFs declines significantly following the introduction of WEBS. The mean (median) value of the change in the spread is about $-2.7 \%(-6.8 \%)$. The abnormal reduction is about $3.5 \%$ for the mean and $8.2 \%$ for the median, statistically significant. These numbers are comparable to those from Hegde and McDermott (2004) who find a 3.1\% (3.5\%) decrease in the mean (median). Similarly, Panel D exhibits a significant drop in the percentage spread; the mean (median) change is about $1.6 \%$ (5.9\%) for the raw numbers and 3.3\% (10.4\%) for the abnormal numbers. The comparable raw numbers reported by Kumar et al. (1998) and Hegde and McDermott (2004) are 5.2\% (9.1\%) and 9.4\% (9.2\%), respectively. 
Table 3

Quoted liquidity for closed-end country funds after the introduction of WEBS.

\begin{tabular}{|c|c|c|c|c|}
\hline Ticker symbol & Pre-level & Post-level & Post/pre & Target ratio/control ratio \\
\hline \multicolumn{5}{|c|}{ Panel A. Change in dollar depth (thousand dollars) } \\
\hline BZF & 41.0 & 57.9 & 1.415 & 0.731 \\
\hline BZL & 17.5 & 38.2 & 2.181 & 1.262 \\
\hline CEF & 27.6 & 23.8 & 0.864 & 1.273 \\
\hline $\mathrm{CHN}$ & 93.2 & 99.0 & 1.062 & 0.693 \\
\hline FRF & 98.4 & 275.6 & 2.799 & 1.886 \\
\hline FRG & 16.5 & 12.8 & 0.778 & 0.877 \\
\hline $\mathrm{GCH}$ & 67.3 & 128.0 & 1.902 & 1.283 \\
\hline GER & 286.0 & 370.9 & 1.297 & 2.315 \\
\hline GF & 341.6 & 745.9 & 2.184 & 2.176 \\
\hline GSP & 268.4 & 190.7 & 0.710 & 0.950 \\
\hline IAF & 35.0 & 72.4 & 2.068 & 1.573 \\
\hline ITA & 120.5 & 149.8 & 1.243 & 1.391 \\
\hline JEQ & 100.1 & 107.6 & 1.076 & 0.644 \\
\hline JFC & 35.9 & 81.9 & 2.280 & 0.715 \\
\hline JOF & 55.3 & 93.0 & 1.682 & 0.588 \\
\hline KEF & 24.9 & 16.1 & 0.649 & 1.073 \\
\hline $\mathrm{KF}$ & 100.1 & 102.9 & 1.028 & 0.879 \\
\hline KIF & 27.4 & 22.9 & 0.834 & 0.980 \\
\hline MEF & 105.1 & 120.7 & 1.148 & 1.082 \\
\hline $\mathrm{MF}$ & 41.4 & 108.8 & 2.631 & 1.884 \\
\hline MXE & 64.7 & 197.3 & 3.049 & 1.425 \\
\hline MXF & 293.6 & 459.3 & 1.565 & 2.777 \\
\hline OST & 175.6 & 220.1 & 1.254 & 1.989 \\
\hline SGF & 30.4 & 47.2 & 1.550 & 0.813 \\
\hline SNF & 21.3 & 14.5 & 0.683 & 0.633 \\
\hline SWZ & 129.9 & 137.8 & 1.061 & 0.949 \\
\hline $\mathrm{TCH}$ & 143.3 & 170.2 & 1.188 & 0.889 \\
\hline TWN & 58.3 & 61.0 & 1.046 & 1.952 \\
\hline UKM & 3.9 & 3.7 & 0.938 & 1.141 \\
\hline Mean & 97.4 & 142.4 & $1.454^{* * *}$ & 1.270 \\
\hline Median & 64.7 & 102.9 & $1.243^{* * *}$ & $1.082^{* * *}$ \\
\hline \multicolumn{5}{|c|}{ Panel B. Changes in depth (hundred shares) } \\
\hline BZF & 12.86 & 16.02 & 1.245 & 0.713 \\
\hline BZL & 16.30 & 31.57 & 1.937 & 1.248 \\
\hline CEF & 27.35 & 23.15 & 0.846 & 1.276 \\
\hline $\mathrm{CHN}$ & 34.47 & 39.64 & 1.150 & 0.665 \\
\hline FRF & 48.44 & 136.28 & 2.813 & 2.072 \\
\hline FRG & 10.76 & 8.83 & 0.821 & 0.874 \\
\hline $\mathrm{GCH}$ & 21.04 & 47.04 & 2.236 & 1.339 \\
\hline GER & 121.21 & 160.84 & 1.327 & 2.298 \\
\hline GF & 139.74 & 309.34 & 2.214 & 2.139 \\
\hline GSP & 121.89 & 83.80 & 0.688 & 0.883 \\
\hline IAF & 18.89 & 39.46 & 2.089 & 1.826 \\
\hline ITA & 72.78 & 90.87 & 1.249 & 1.426 \\
\hline JEQ & 37.30 & 41.55 & 1.114 & 0.670 \\
\hline JFC & 14.47 & 36.70 & 2.537 & 0.691 \\
\hline JOF & 30.14 & 52.62 & 1.746 & 0.562 \\
\hline KEF & 32.52 & 21.90 & 0.673 & 1.084 \\
\hline $\mathrm{KF}$ & 33.50 & 38.43 & 1.147 & 0.939 \\
\hline $\mathrm{KIF}$ & 18.38 & 17.17 & 0.934 & 0.991 \\
\hline MEF & 77.53 & 83.80 & 1.081 & 1.156 \\
\hline $\mathrm{MF}$ & 10.54 & 27.59 & 2.618 & 1.858 \\
\hline MXE & 35.53 & 96.84 & 2.726 & 1.308 \\
\hline MXF & 101.18 & 148.76 & 1.470 & 2.424 \\
\hline OST & 98.32 & 125.58 & 1.277 & 1.969 \\
\hline SGF & 10.51 & 17.23 & 1.639 & 0.902 \\
\hline SNF & 11.57 & 7.70 & 0.665 & 0.650 \\
\hline SWZ & 30.15 & 32.27 & 1.070 & 1.008 \\
\hline $\mathrm{TCH}$ & 58.99 & 76.67 & 1.300 & 1.074 \\
\hline
\end{tabular}


Table 3 (Continued)

\begin{tabular}{|c|c|c|c|c|}
\hline Ticker symbol & Pre-level & Post-level & Post/pre & Target ratio/control ratio \\
\hline TWN & 13.91 & 17.72 & 1.274 & 1.766 \\
\hline UKM & 1.59 & 1.47 & 0.923 & 1.048 \\
\hline Mean & 43.51 & 63.13 & $1.476^{* * *}$ & 1.271 \\
\hline Median & 30.15 & 39.46 & $1.274^{* * *}$ & $1.084^{* * *}$ \\
\hline \multicolumn{5}{|c|}{ Panel C. Changes in dollar spread } \\
\hline $\mathrm{BZF}$ & 0.316 & 0.300 & 0.949 & 2.690 \\
\hline BZL & 0.279 & 0.261 & 0.933 & 0.918 \\
\hline CEF & 0.143 & 0.132 & 0.923 & 0.921 \\
\hline $\mathrm{CHN}$ & 0.216 & 0.210 & 0.971 & 1.034 \\
\hline FRF & 0.204 & 0.161 & 0.791 & 0.641 \\
\hline FRG & 0.156 & 0.153 & 0.982 & 0.926 \\
\hline $\mathrm{GCH}$ & 0.272 & 0.238 & 0.876 & 0.807 \\
\hline GER & 0.152 & 0.139 & 0.910 & 0.783 \\
\hline GF & 0.174 & 0.141 & 0.809 & 0.814 \\
\hline GSP & 0.184 & 0.181 & 0.984 & 0.981 \\
\hline IAF & 0.216 & 0.142 & 0.657 & 0.867 \\
\hline ITA & 0.163 & 0.156 & 0.956 & 0.902 \\
\hline JEQ & 0.171 & 0.189 & 1.103 & 0.972 \\
\hline JFC & 0.371 & 0.240 & 0.647 & 0.913 \\
\hline JOF & 0.200 & 0.183 & 0.911 & 0.974 \\
\hline KEF & 0.226 & 0.275 & 1.218 & 0.901 \\
\hline $\mathrm{KF}$ & 0.270 & 0.248 & 0.917 & 0.961 \\
\hline KIF & 0.325 & 0.325 & 1.002 & 1.141 \\
\hline MEF & 0.187 & 0.185 & 0.991 & 0.946 \\
\hline $\mathrm{MF}$ & 0.349 & 0.287 & 0.822 & 0.680 \\
\hline MXE & 0.245 & 0.179 & 0.730 & 0.964 \\
\hline MXF & 0.202 & 0.188 & 0.932 & 0.754 \\
\hline OST & 0.158 & 0.152 & 0.959 & 0.837 \\
\hline SGF & 0.307 & 0.250 & 0.815 & 0.916 \\
\hline SNF & 0.143 & 0.154 & 1.077 & 1.114 \\
\hline SWZ & 0.293 & 0.274 & 0.936 & 0.886 \\
\hline $\mathrm{TCH}$ & 0.195 & 0.178 & 0.915 & 0.880 \\
\hline TWN & 0.358 & 0.308 & 0.860 & 0.927 \\
\hline UKM & 0.286 & 0.759 & 2.653 & 0.949 \\
\hline Mean & 0.233 & 0.227 & 0.973 & $0.965^{* *}$ \\
\hline Median & 0.216 & 0.188 & $0.932^{* * *}$ & $0.918^{* *}$ \\
\hline \multicolumn{5}{|c|}{ Panel D. Changes in percentage spread } \\
\hline $\mathrm{BZF}$ & 1.979 & 1.665 & 0.841 & 2.584 \\
\hline BZL & 5.237 & 4.331 & 0.827 & 0.896 \\
\hline CEF & 2.867 & 2.613 & 0.911 & 0.889 \\
\hline $\mathrm{CHN}$ & 1.552 & 1.623 & 1.046 & 0.971 \\
\hline FRF & 2.015 & 1.595 & 0.792 & 0.673 \\
\hline FRG & 2.063 & 2.091 & 1.014 & 0.933 \\
\hline $\mathrm{GCH}$ & 1.708 & 1.739 & 1.018 & 0.819 \\
\hline GER & 1.296 & 1.199 & 0.925 & 0.778 \\
\hline GF & 1.423 & 1.178 & 0.828 & 0.838 \\
\hline GSP & 1.689 & 1.542 & 0.913 & 0.939 \\
\hline IAF & 2.419 & 1.550 & 0.641 & 1.000 \\
\hline ITA & 2.010 & 1.905 & 0.948 & 0.873 \\
\hline JEQ & 1.277 & 1.465 & 1.148 & 0.996 \\
\hline JFC & 3.148 & 2.156 & 0.685 & 0.895 \\
\hline JOF & 2.293 & 2.038 & 0.889 & 0.896 \\
\hline KEF & 5.656 & 7.603 & 1.344 & 0.908 \\
\hline $\mathrm{KF}$ & 1.887 & 1.806 & 0.957 & 1.027 \\
\hline KIF & 4.463 & 4.830 & 1.082 & 1.162 \\
\hline MEF & 2.760 & 2.638 & 0.956 & 0.998 \\
\hline $\mathrm{MF}$ & 1.756 & 1.497 & 0.853 & 0.649 \\
\hline MXE & 2.566 & 1.797 & 0.700 & 0.871 \\
\hline MXF & 1.405 & 1.209 & 0.860 & 0.709 \\
\hline
\end{tabular}


Table 3(Continued)

\begin{tabular}{lccll}
\hline Ticker symbol & Pre-level & Post-level & Post/pre & Target ratio/control ratio \\
\hline OST & 1.834 & 1.725 & 0.941 & 0.838 \\
SGF & 2.175 & 1.814 & 0.834 & 0.986 \\
SNF & 1.554 & 1.595 & 1.027 & 1.225 \\
SWZ & 1.342 & 1.275 & 0.950 & 0.904 \\
TCH & 1.600 & 1.577 & 0.986 & 1.084 \\
TWN & 1.683 & 1.746 & 1.037 & 0.838 \\
UKM & 2.362 & 6.116 & 2.589 & 0.877 \\
Mean & 2.277 & 2.273 & 0.984 & $0.967^{* *}$ \\
Median & 1.979 & 1.739 & $0.941^{* *}$ & $0.896^{*}$ \\
\hline
\end{tabular}

For each closed-end fund, we first obtain time-weighted quoted spread and depth for each trading day, where the time is the length of time the spread is posted relative to the length of the trading day. Depth is the average number of shares available at the bid and at ask price for a given quote. We present the median of these averages for the 3 months before and the 3 months after the introduction of the WEBS. We calculate the ratio of the post-introduction level to the pre-introduction level. In the last column, we report the ratio of the post/pre ratio of target CECFs to the average ratio of control sample. Each event date, we rank the universe of closed-end funds into quintiles based on the average of daily trading volume during the previous 3 months. Those that are in the same volume quintile as the target CECFs and that are not associated with any WEBS introduction will serve as the control sample for that target CECFs.

The significant levels for mean and median of the ratio are determined by standard $t$-test and Wilcoxon signed-rank test, respectively. ${ }^{* * *},{ }^{* *}$, and ${ }^{*}$ denote significant at $0.01,0.05$, and 0.1 , respectively.

The signed-rank test statistic $S$ is computed as $S=\sum_{i ; x_{i}>0} r_{i}^{+}-\left(n_{t}\left(n_{t}+1\right) / 4\right)$ where $(\mathrm{i}) r_{i}^{+}$is the rank of the absolute difference between the individual ratio and 1 , which underlies the hypothesis that there is no significant changes in trading activities for CECFs around the introduction of WEBS and (ii) $n_{t}$ is the number of observations not equal to 1 . For details for the test procedure, refer to Lehmann (1998).

The findings in Tables 2 and 3 support the view that liquidity for CECFs improved following the introduction of WEBS. The reduction in trading volume, and more importantly, the reduction in the daily number of trades, implies a reduction in the size of the market for CECFs. This result is expected because WEBS substitute for CECFs with favorable features such as lower tracking error, much lower discounts or premia and better tax treatment. However, market size alone does not reflect every aspect of market liquidity. According to Black (1971) and Kyle (1985), market liquidity is characterized by the 'tightness', represented by the size of the bid-ask spread and 'depth' represented by quote depth. From this point of view, the liquidity of CECFs has significantly improved following the start of WEBS trading.

Based on the literature, there are two potential reasons for the observed results. First, with better tracking error and freedom from the uptick rule, WEBS could better facilitate speculation and hence appear to attract informed traders who possess information pertinent to a specific country. The migration of these traders helps to reduce the information asymmetry in the CECFs market (Hegde \& McDermott, 2004; Kumar et al., 1998). At the same time, the availability of a new market will increase the market-wide level of public information, and hence lower the information asymmetry (Kumar et al., 1998). Second, the availability of WEBS provides a new form of access to restricted international markets, thus reducing market segmentation and improving market efficiency (O'Connor \& Downe, 2000; Patro, 2001). In sum, these developments could reduce the adverse selection cost for the CECFs, and thus increase market depth and reduce bid-ask spreads.

Next, we examine the difference between CECFs and their corresponding WEBS in terms of the bid-ask spread. Since WEBS have investment and trading advantages over CECFs, we are interested in how the bid-ask spreads for WEBs compare with those for the CECFs. In Table 4 , we report the median value of spread for WEBS and for CECFs over the 3-month period following the introduction of WEBS. We find that spreads for WEBS are significantly lower than for CECFs. For the dollar spread, the CECFs' trading cost is higher than that of WEBS by about $32 \%(17 \%)$ in mean (median) value. The corresponding disadvantage for the percentage spread is $70 \%$ (52\%). All numbers are statistically significant.

In sum, our analysis indicates that after the introduction of WEBS, trading volume of CECFs decreases due to a substitution effect, and at the same time other aspects of liquidity for CECFs improved. Specif- 
Table 4

Comparison of liquidity between closed-end country funds and their corresponding WEBS.

\begin{tabular}{|c|c|c|c|}
\hline Ticker symbol & Dollar spread of CECF & Dollar spread of WEBS & Spread ratio \\
\hline \multicolumn{4}{|c|}{ Panel A. Comparison of dollar spread } \\
\hline $\mathrm{BZF}$ & 0.300 & 0.742 & 0.404 \\
\hline BZL & 0.261 & 0.742 & 0.351 \\
\hline CEF & 0.132 & 0.188 & 0.702 \\
\hline CHN & 0.210 & 0.128 & 1.634 \\
\hline FRF & 0.161 & 0.129 & 1.244 \\
\hline FRG & 0.153 & 0.125 & 1.221 \\
\hline $\mathrm{GCH}$ & 0.238 & 0.128 & 1.854 \\
\hline GER & 0.139 & 0.125 & 1.105 \\
\hline GF & 0.141 & 0.125 & 1.121 \\
\hline GSP & 0.181 & 0.151 & 1.200 \\
\hline IAF & 0.142 & 0.125 & 1.135 \\
\hline ITA & 0.156 & 0.152 & 1.025 \\
\hline JEQ & 0.189 & 0.115 & 1.641 \\
\hline JFC & 0.240 & 0.128 & 1.870 \\
\hline JOF & 0.183 & 0.115 & 1.585 \\
\hline KEF & 0.275 & 0.480 & 0.573 \\
\hline $\mathrm{KF}$ & 0.248 & 0.480 & 0.516 \\
\hline KIF & 0.325 & 0.480 & 0.677 \\
\hline MEF & 0.185 & 0.159 & 1.169 \\
\hline MF & 0.287 & 0.141 & 2.032 \\
\hline MXE & 0.179 & 0.159 & 1.130 \\
\hline MXF & 0.188 & 0.159 & 1.185 \\
\hline OST & 0.152 & 0.160 & 0.945 \\
\hline SGF & 0.250 & 0.125 & 2.000 \\
\hline SNF & 0.154 & 0.151 & 1.021 \\
\hline SWZ & 0.274 & 0.144 & 1.905 \\
\hline $\mathrm{TCH}$ & 0.178 & 0.128 & 1.389 \\
\hline TWN & 0.308 & 0.556 & 0.555 \\
\hline UKM & 0.759 & 0.149 & 5.081 \\
\hline Mean & 0.227 & 0.231 & $1.320^{*}$ \\
\hline Median & 0.188 & 0.149 & $1.169^{* *}$ \\
\hline Ticker symbol & Percentage spread & Percentage spread of WEBS & Spread ratio \\
\hline \multicolumn{4}{|c|}{ Panel B. Comparison of percentage spread } \\
\hline BZF & 1.665 & 3.926 & 0.424 \\
\hline BZL & 4.331 & 3.926 & 1.103 \\
\hline CEF & 2.613 & 1.760 & 1.485 \\
\hline CHN & 1.623 & 0.942 & 1.723 \\
\hline FRF & 1.595 & 0.976 & 1.634 \\
\hline FRG & 2.091 & 0.959 & 2.180 \\
\hline $\mathrm{GCH}$ & 1.739 & 0.942 & 1.845 \\
\hline GER & 1.199 & 0.959 & 1.250 \\
\hline GF & 1.178 & 0.959 & 1.228 \\
\hline GSP & 1.542 & 1.050 & 1.468 \\
\hline IAF & 1.550 & 1.205 & 1.287 \\
\hline ITA & 1.905 & 1.035 & 1.841 \\
\hline JEQ & 1.465 & 0.726 & 2.018 \\
\hline JFC & 2.156 & 0.942 & 2.288 \\
\hline JOF & 2.038 & 0.726 & 2.808 \\
\hline KEF & 7.603 & 2.336 & 3.254 \\
\hline $\mathrm{KF}$ & 1.806 & 2.336 & 0.773 \\
\hline KIF & 4.830 & 2.336 & 2.067 \\
\hline MEF & 2.638 & 1.348 & 1.957 \\
\hline $\mathrm{MF}$ & 1.497 & 1.015 & 1.475 \\
\hline MXE & 1.797 & 1.348 & 1.333 \\
\hline MXF & 1.209 & 1.348 & 0.897 \\
\hline OST & 1.725 & 1.461 & 1.180 \\
\hline SGF & 1.814 & 0.990 & 1.832 \\
\hline SNF & 1.595 & 1.050 & 1.519 \\
\hline
\end{tabular}


Table 4(Continued)

\begin{tabular}{llll}
\hline Ticker symbol & Percentage spread & Percentage spread of WEBS & Spread ratio \\
\hline SWZ & 1.275 & 1.180 & 1.081 \\
TCH & 1.577 & 0.942 & 1.674 \\
TWN & 1.746 & 3.212 & 0.544 \\
UKM & 6.116 & 1.197 & 5.110 \\
Mean & 2.273 & 1.487 & $1.699^{* * *}$ \\
Median & 1.739 & 1.050 & $1.519^{* * *}$ \\
\hline
\end{tabular}

Over the 3 month after the introduction dates of the WEBS that correspond to each closed-end fund, we obtain time-weighted quoted spread and depth for each trading day, where the weight is the duration of each quote relative to the length of the trading day. We then compare the median of these averages with the corresponding numbers for the WEBS over the same period by calculating the ratio of the CECFs to the WEBS.

The significant levels for mean and median of the ratio are determined by standard $t$-test and Wilcoxon signed-rank test, respectively. ${ }^{* * *},{ }^{* *}$, and ${ }^{*}$ denote significant at $0.01,0.05$, and 0.1 , respectively. The signed-rank test statistic $S$ is computed as $S=\sum_{i ; x_{i}>0} r_{i}^{+}-\left(n_{t}\left(n_{t}+1\right) / 4\right)$ where (i) $r_{i}^{+}$is the rank of the absolute difference between the individual ratio and 1 , which underlies the hypothesis that there is no significant difference between WEBS and CECFs and (ii) $n_{t}$ is the number of observations not equal to 1 . For details for the test procedure, refer to Lehmann (1998).

ically, we demonstrate a decline in the bid-ask spread and an increase in the quote depth. Further, we find that the frequency of trades and daily trading volume decrease for CECFs, although there is no significant change in their average trade size. However, despite these improvements in the liquidity of CECFs, this older vehicle is inferior to WEBS in terms of overall liquidity.

Our findings are consistent with Kumar et al. (1998) and Hegde and McDermott (2004) who document that informed traders migrate to the new market which possesses more favorable features for speculative purposes, lowering information asymmetry and improving liquidity of the traditional market.

\section{Conclusions}

The received literature documents that the introduction of a complementary vehicle could affect the operational efficiency of the original market. In this paper, we extend the literature by examining changes in the liquidity of the market for CECFs around the advent of World Equity Benchmark Shares (WEBS). While the introduction of new market could negatively affect the size of the original market, the availability of WEBS could also favorably influence the liquidity condition for CECFs. The reasons suggested by the literature are that: first, WEBS might attract informed traders away from the CECFs market because the emergence of the WEBS market better serves speculative trading and positioning; and second, the existence of the new market will increase market-wide public information. Therefore liquidity improves for CECFs.

Our empirical findings support the above anticipations. First, we document that CECFs trading activity falls following the introduction of WEBS. This is primarily caused by a reduction in the number of trades rather than by a reduction in the individual trade size. Second, we find that the liquidity for CECFs is favorably affected by the introduction of WEBS. Specifically, CECFs experience narrower bidask spreads and deeper quote depth. Finally, comparing CECFs with corresponding their WEBS, we find that bid-ask spreads for CECFs are still higher than those for WEBS, which suggests that WEBS with their more favorable features such as the creation/redemption mechanism, freedom from shortsale restrictions, tax-efficiency and lower tracking error are a better and more cost-efficient avenue to global portfolio diversification.

\section{Acknowledgements}

We thank the anonymous referee who helped us to improve the paper. We also thank participants at the 2007 Southern Finance Association meeting, and the 2008 Financial Management Association meeting as well as and participants in the research seminar series at the Merrick School of Business for helpful comments. 


\section{References}

Black, F. (1971). Towards a fully automated exchange, part 1. Financial Analysts Journal, 27, 29-34.

Chang, E., \& Swales, G. (2003). Do country-specific exchange-traded funds outperform closed-end country funds? Working paper. Southwest Missouri University.

Chen, H., Noronha, G., \& Singal, V. (2004). The price response to S\&P 500 Index additions and deletions: Evidence of asymmetry and a new explanation. Journal of Finance, 59, 1901-1929.

Choi, H., \& Subrahmanyam, A. (1994). Using intraday data to test for effects of index futures on the underlying stock markets. Journal of Futures Markets, 14, 293-322.

Gastineau, G. (2001). Exchange traded funds: An introduction. Journal of Portfolio Management, 27, 88-96.

Gastineau, G. (2002). The exchange traded funds manual. New York: Wiley.

Gorton, G., \& Pennacchi, G. (1993). Security baskets and index-linked securities. Journal of Business, 66, 1-27.

Harper, J., Madura, J., \& Schnusenberg, O. (2006). Performance comparison between exchange traded funds and closed-end country funds. Journal of International Financial Markets, 16, 106-122.

Hegde, S., \& McDermott, J. (2004). The market liquidity of DIAMONDS, Q's, and their underlying stocks. Journal of Banking and Finance, 28, 1043-1067.

Jegadeesh, N., \& Subrahmanyam, A. (1993). Liquidity effects of the introduction of the S\&P 500 index futures contract on the underlying stocks. Journal of Business, 66, 171-187.

Khorana, A., Nelling, E., \& Trester, J. (1998). The emergence of country index funds. Journal of Portfolio Management, $24,78-84$.

Kumar, R., Sarin, A., \& Shastri, K. (1998). The impact of options trading on the market quality of the underlying security: An empirical analysis. Journal of Finance, 53, 717-732.

Kyle, A. (1985). Continuous action and insider trading. Econometrica, 53, 1315-1336.

Lee, B., \& Hong, G. (2002). On the dual characteristics of closed-end country funds. Journal of International Money and Finance, 21, 589-618.

Lehmann, E. L. (1998). Nonparametrics: Statistical methods based on ranks. Upper Saddle River, N.J.: Prentice Hall.

Miffre, J. (2007). Country-specific ETFs: An efficient approach to global asset allocation. Journal of Asset Management, 8(2), $112-122$.

O'Connor, M., \& Downe, E. (2000). The effect of country specific index trading on closed-end country funds: An empirical analysis. Financial Services Review, 9, 259-275.

Patro, D. (2001). Market segmentation and international asset prices: Evidence from the listing of world equity benchmark shares. Journal of Financial Research, 24, 83-98.

Patro, D. (2005). Stock market liberalization and emerging market country fund premiums. Journal of Business, 78(1), 135-168.

Pennathur, A., Delcuore, N., \& Anderson, D. (2002). Diversification benefits of iShares and closed end country funds. Journal of Financial Research, 25, 541-557.

Phengpis, C., \& Swanson, P. E. (2004). Increasing input information and realistically measuring potential diversification gains from international portfolio investments. Global Finance Journal, 15(2), 197-217.

Poterba, J., \& Shoven, J. (2002). Exchange traded funds: A new investment option for taxable investors. American Economics Review, 92, 422-427.

Subrahmanyam, A. (1991). A theory of trading in stock index futures. Review of Financial Studies, 4, 17-51. 